\title{
Correction to: Dialogic meta-ethnography: troubling methodology in ethnographically informed qualitative inquiry
}

\author{
Brandon J. Sherman ${ }^{2} \cdot$ Kathryn M. Bateman ${ }^{3,4} \cdot$ Sophia Jeong $^{1}$ (D) . \\ Laura Anne Hudock ${ }^{5,6}$
}

Published online: 1 February 2021

(c) Springer Nature B.V. 2021

\section{Correction to: Cultural Studies of Science Education https://doi.org/10.1007/s11422-019-09961-8}

In the original publication, the author name Sophia Jeong was incorrectly published. This has been corrected with this correction.

The original article has been corrected.

Publisher's Note Springer Nature remains neutral with regard to jurisdictional claims in published maps and institutional affiliations.

The original article can be found online at https://doi.org/10.1007/s11422-019-09961-8.

Sophia Jeong

sj33678@uga.edu

Brandon J. Sherman

brandsherman@gmail.com

Kathryn M. Bateman

kmb1182@gmail.com

Laura Anne Hudock

lhudock@framingham.edu

1 Department of Biochemistry and Molecular Biology, University of Georgia, B122 Life Sciences Bldg., Athens, GA 30602, USA

2 College of Education, IUPUI, Indianapolis, IN, USA

3 Department of Curriculum \& Instruction, The Pennsylvania State University, University Park, PA, USA

4 Present Address: Department of Psychology, Temple University, Philadelphia, PA, USA

5 Curriculum \& Instruction, The Pennsylvania State University, University Park, PA, USA

6 Present Address: College of Education at Framingham State University, Framingham, MA, USA 